\title{
Sorghum Root Flavonoid Chemistry, Cultivar, and Frost Stress Effects on Rhizosphere Bacteria and Fungi
}

\author{
Mara Cloutier, ${ }^{1, \dagger}$ Debamalya Chatterjee, ${ }^{2}$ Dinakaran Elango, ${ }^{2}$ Jin Cui, ${ }^{2}$ Mary Ann Bruns, ${ }^{1}$ and Surinder Chopra ${ }^{2, \dagger}$ \\ ${ }^{1}$ Department of Ecosystem Science and Management, The Pennsylvania State University, University Park, PA \\ ${ }^{2}$ Department of Plant Science, The Pennsylvania State University, University Park, PA
}

Accepted for publication 12 July 2020.

ABSTRACT

\begin{abstract}
Biotic stresses, including fungal infections, result in increased production of flavonoid compounds, including 3-deoxyanthocyanidins (3-DAs), in the leaf tissues of Sorghum bicolor. Our objectives were to determine whether sorghum genotypic variation influenced root flavonoid and 3-DA concentrations and rhizosphere microbial communities and to identify how these relationships were affected by abiotic stress. We evaluated root chemicals and rhizosphere microbiomes of five near-isogenic lines of sorghum before and after a late-season frost. Roots were analyzed for total flavonoids, total phenolics, 3-DA concentrations, and antioxidant activity. Amplicon sequencing of $16 \mathrm{~S}$ ribosomal RNA genes and internal transcribed spacer regions was performed on rhizosphere soils. Concentrations of luteolinidin (a 3-DA) and total flavonoids differed between several lines before frost; however, these relationships changed after frost. Luteolinidin increased in three lines after frost, whereas total flavonoids decreased in all the lines after frost. Lines that differed in luteolinidin
\end{abstract}

and total flavonoid concentrations before frost were different from those after frost. Rhizosphere community compositions also differed before and after frost but only fungal community compositions differed among sorghum lines. Bacterial community compositions were highly correlated with total flavonoid and luteolinidin concentrations.

Furthermore, a greater number of bacterial taxa were correlated with total flavonoids and luteolinidin compared with fungal taxa. Collectively, this study provides evidence that plant genotypic variation influences root flavonoids and rhizosphere community composition and that these relationships are affected by frost. Plant-microbe interactions and secondary metabolite production may be important components to include for selective breeding of sorghum for frost stress tolerance.

Keywords: 3-deoxyanthocyanidins, 16S rRNA, agriculture, crop, flavonoids, frost, ITS, luteolinidin, microbiome, phyllosphere, rhizosphere, sorghum
${ }^{\dagger}$ Corresponding authors: M. Cloutier; muc345@psu.edu; and S. Chopra; sic3@psu.edu

Author contributions: M.C., S.C., D.C., D.E., and M.A.B. designed the experiments; M.C., D.C., D.E., and J.C. performed the experiments; M.C., D.C., and D.E. analyzed the data; S.C. and M.A.B. contributed to data analysis; and M.C., S.C., D.C., D.E. and M.A.B. wrote the manuscript. All authors approved the final manuscript.

Funding: Funding was provided by a SDSU Sun Grant Initiative Penn State subaward 3TG640 to S.C. and M.A.B. S.C. was also supported by United States Department of Agriculture (USDA) National Institute of Food and Agriculture awards 2011-67009-30017 and 2019-70006-30442, and USDA Hatch awards PEN04330 and PEN04613. M.A.B. received support from USDA Hatch awards PEN4402 and PEN4571. Additional support was provided by grant 1009145. Graduate students D.C., D.E. and J.C. were partially supported by a Sun Grant Initiative award and graduate fellowships from Plant Science Department. J.C. was partially supported by a University Graduate Fellowship through the Plant Biology program. D.C. was partially supported by an international graduate fellowship from the Indian Council of Agricultural Research.

*The $e$-Xtra logo stands for "electronic extra" and indicates that supplementary materials are published online.

The author(s) declare no conflict of interest.

(C) 2021 The American Phytopathological Society
Sorghum bicolor (L.) Moench is the fifth most valuable cereal crop globally. Not only can $S$. bicolor be used for food and feed (Reddy et al. 2012), it can also be grown as a bioenergy crop and produces more ethanol than maize when grown on marginal lands (Maw et al. 2017). Sorghum is better adapted to stresses such as drought, salinity, and heat, which may be partially due to sorghum's higher water and nitrogen use efficiency (Reddy and Reddy 2003; Rooney et al. 2007; Schittenhelm and Schroetter 2014). Considering the multifunctionality of sorghum and its resilience against environmental stresses, it is not surprising that production of sorghum has been on the rise for the last 50+ years (FAOSTAT, data from 1960 to 2018). Increased sorghum production in the face of climate change calls for improving its tolerance to abiotic and biotic stresses that can limit productivity (Hagan et al. 2014; Hoffmann and Rooney 2014; Tetreault et al. 2019).

Although sorghum is relatively tolerant to drought and high temperatures, it is very sensitive to chilling, frost, and freezing stresses. Cold-temperature stresses on sorghum result in reduced grain size and seed germination (Roozeboom and McKinney 2009; 
Staggenborg and Vanderlip 1996; Staggenborg et al. 1999). Sorghum production in southern Canada and the northern United States is particularly affected by cold-related stress. Sorghum flowering peaks in fall and early winter, when days are cooler (Singh 1985), which is a problem because cold stresses can lead to male sterility (Wood et al. 2006). Identifying genotypes of sorghum or specific genes that confer resistance to cold stresses is important for increased production at higher latitudes, and these genotypes are actively being explored (Moghimi et al. 2019; Parra-Londono et al. 2017).

Apart from apparent alterations to seed germination and grain size, low temperatures affect metabolite production in sorghum, including increased production of unsaturated fatty acids and reactive oxygen species (ROS) (Guo et al. 2016). Antioxidant synthesis is activated by ROS and includes compounds such as flavonoids and phenolics. Plant production of flavonoids and phenolics increases under stress (Guidi et al. 2016; Kawahigashi et al. 2016; Tattini et al. 2005). Flavonoid metabolites have positive correlations with protective traits in diverse crops under frost stress (Jensen et al. 2012; Schulz et al. 2016; Treutter 2006). A variety of flavonoid and phenolic metabolites are produced by sorghum through the phenylpropanoid pathway and include flavan-4-ols (Winkel-Shirley 2001). Flavan-4-ols are precursor molecules for 3-deoxyanthocyanidins (3-DAs) and include specific metabolites such as luteolinidin and apigeninidin (Boddu et al. 2005; Grotewold et al. 1998; Ibraheem et al. 2010; Lo and Nicholson 1998; Rhodes et al. 2017). In sorghum, 3-DAs are synthesized de novo in response to both pathogenic (Colletotrichum sublineola, Ascochyta sorghi, and Bipolaris sorghicola) and nonpathogenic (Cochliobolus heterostrophus) fungal incursions, thereby conferring resistance to these fungi (Ibraheem et al. 2010, 2015; Mizuno et al. 2012; Nicholson et al. 1987).

Sorghum is recognized for its ability to produce flavonoids (Nielsen et al. 2004) as well as large amounts of exudates (Baerson et al. 2007). The composition of sorghum rhizosphere exudates, including type and amount, are genotype dependent (Miller et al. 2019). Flavonoids have antibacterial and antifungal properties (Górniak et al. 2019) but are also reported to serve as chemical signals to support rhizobium-legume and arbuscular mycorrhizal symbioses (Abdel-Lateif et al. 2012). Several studies have reported the effects of root exudates in shaping the composition of rhizosphere microbiomes (Broeckling et al. 2008; Cotton et al. 2019; Hu et al. 2018; White et al. 2017), and the roles of root microbiomes in mitigating abiotic stresses is increasingly being highlighted (de Vries et al. 2020). More information is needed on how flavonoids produced in sorghum roots might influence rhizosphere microbial assemblages and whether frost stress affects root flavonoid production.

In this study, we aimed to determine whether late-season frost affected the concentrations of key root chemicals and antioxidant activity of field-grown sorghum. Considering the potential for flavonoids to act as signaling compounds for rhizosphere microorganisms, we set out to determine whether rhizosphere bacterial and fungal communities differed among near-isogenic lines (NILs) of sorghum varying in 3-DA production in leaves and to assess correlations between concentrations of flavonoid compounds and abundances of microbial taxa. These NILs, which share approximately $97 \%$ of their nuclear genes, with the exception of those controlling seed or pericarp color and necrotic plant color (Pedersen and Toy 2001a, b), were also shown previously to vary in aboveground 3-DA concentrations. Given the difficulties in analyzing root exudates in field soils, we analyzed root tissue samples before and after frost for total flavonoids, 3-DAs (apigeninidin, and luteolinidin), total phenolics, and antioxidant activity. We also analyzed rhizosphere soil microbial communities using sequencing of the $16 \mathrm{~S}$ ribosomal RNA (rRNA) genes and internal transcribed spacer (ITS) regions. Overall this study demonstrates that near-isogenic lines can be used to exploit the power of plant genetics to better understand variability and associations of rhizosphere microbiomes.

\section{MATERIALS AND METHODS}

Root chemical analyses, rhizosphere community sample processing and analysis, and statistical analyses are provided in Supplementary File S1. Brief materials and methods are described below.

Sorghum NILs. Complete documentation of the provenance of sorghum lines has been described previously (Pedersen and Toy 2001a,b). The five NILs of S. bicolor (L.) Moench used in this study differ in their pericarp and plant pigmentation and also in their 3-DA content in leaf and grain. Lines N321 and N326 are classified as 3DA nonproducers, N334 and N336 are classified as 3-DA producers, and N337 is classified as an induced producer that synthesizes 3-DA compounds after biotic stresses (I. Gaffoor and S. Chopra, unpublished). These lines are expected to share approximately $97 \%$ of their nuclear genes, except for those controlling seed or pericarp color and plant color (Pedersen and Toy 2001b), including luteolinidin and apigeninidin compounds (I. Gaffoor and S. Chopra, unpublished).

Site description, experimental design, and rhizosphere sampling. A field experiment was conducted during the 2018 growing season at the Russell Larson Research Farm of the Pennsylvania State University $\left(40^{\circ} 43^{\prime} \mathrm{N}, 77^{\circ} 56^{\prime} \mathrm{W}, 372 \mathrm{~m}\right.$ in elevation). Four-row plots per replicate of each of the five sorghum NILs were planted using a randomized complete block design with four replications. Three plants per line/replicate were excavated for root and soil sample collections. Plant rhizospheres were sampled before (52 days after planting) and 10 days (111 days after planting) after frost by digging up each plant to a depth of 15 to $20 \mathrm{~cm}$ and diameter of 10 to $12 \mathrm{~cm}$ around the plant base. In the field, roots were vigorously shaken to remove excess bulk soil. Samples were placed in a Ziploc bag, stored in a cooler with ice, and transported to the laboratory. After removing roots from the Ziploc bags, the remaining excess bulk soil was removed. We classified rhizosphere soil as the soil tightly adhering to the roots (approximately 2-mm distance from root). Sterile water $(50 \mathrm{ml})$ was added to each bag and roots were manually massaged to separate the soil associated with the rhizosphere. Samples were pooled, transferred to falcon tubes, and centrifuged at $10,000 \mathrm{rpm}$ for $20 \mathrm{~min}$ to pellet the soil. Washed root samples were frozen in liquid nitrogen and immediately ground. All samples were stored at $-80^{\circ} \mathrm{C}$ until further analysis.

Root chemical quantification. Subsamples of sorghum roots were ground in liquid nitrogen. Chemical extraction was performed with methanol acidified with $0.1 \%$ ( $\mathrm{vol} / \mathrm{vol}$ ) hydrochloric acid using $50 \mathrm{mg}$ of ground root $\mathrm{ml}^{-1}$ of extractant. These extracts were then used to quantify different root chemical fractions. Total phenolic content was assessed by mixing a subsample of the extract with the Folin-Ciocalteu reagent and sodium carbonate. Absorbance values $(765 \mathrm{~nm})$ were compared against a gallic acid standard. Total flavonoids were quantified by adding a subsample of the extract to aluminum chloride, potassium acetate, and deionized water. Absorbance values $(510 \mathrm{~nm})$ were compared against a catechin standard. The two compounds measured as 3-DAs were luteolinidin and apigeninidin using absorbances of 480 and $500 \mathrm{~nm}$, respectively, in original acidified methanol extracts. Finally, 2,20-diphenyl-1picrylhydrazyl (DPPH) assays were performed by adding a subsample of the extracts to a DPPH solution diluted in methanol. Absorbance values $(515 \mathrm{~nm})$ were compared against a Trolox equivalent (TE) standard. All values are expressed as milligrams per gram of root. 
ITS and 16S rRNA sequencing and processing. Frozen rhizosphere soil samples were thawed prior to DNA extraction by Wright Labs, LLC for Illumina amplicon sequencing of ITS regions and 16S rRNA genes. Reads were processed following the DADA2 pipeline in $\mathrm{R}$ to assign amplicon sequence variants (ASVs) (Callahan et al. 2016). Taxonomy was assigned with UNITE for ITS sequences (accessed on 12 December 2018) (UNITE Community 2019) and Silva for 16S rRNA sequences (accessed on 3 December 2018) (Quast et al. 2013). General statistics regarding how many sequences were processed and passed certain steps in DADA2 can be found in Supplementary Table S1.

Statistical analyses. Root chemicals. Linear mixed-effect modeling was performed to determine whether root chemical concentrations were different between lines, time, or the combination of lines-time, with block as the random variable. Models were built using lme4 in $\mathrm{R}$ and, if a factor was significant $(P<0.05)$, then pairwise comparisons using emmeans were performed with Tukey $P$ value adjustments (Lenth 2020). Because apigeninidin and luteolinidin were found to be highly correlated (Pearson correlation $>0.99$ ), only luteolinidin concentrations were used for the analyses.

Diversity metrics. $\alpha$ Diversity was calculated for both ITS and 16S rRNA sequences from rarefied sequence counts. Richness (observed ASVs) and Shannon Diversity were calculated, and linear mixed-effect models were created as described above. $\beta$-Diversity metrics used to assess bacterial community composition included Bray-Curtis and weighted UniFrac, while Bray-Curtis alone was used for fungal ITS compositional analyses. Global permutational multivariate analyses of variance (PERMANOVAs) were performed with Adonis and pairwise PERMANOVAs were conducted with the RVAideMemoire package (Hervé 2019).

Differential abundance and correlational analyses. Analyses to identify taxa that were differentially abundant across time and lines were performed using DESeq2 after converting the phyloseq object into a DESeq object (Love et al. 2014). Correlations between ITS or $16 \mathrm{~S} \beta$ diversity and concentrations of root chemicals were assessed using Mantel tests with vegan (Oksanen et al. 2019). The abundances of taxa were correlated with chemical variables using Kendall correlations and correlations of $\geq 0.50$ or $\leq-0.5$ were considered as positively or negatively correlated, respectively, with the chemical variable. In several cases, producer lines (N334 and N336) and nonproducer lines (N321 and N326) were analyzed separately.

Raw sequencing data were submitted to NCBI under the Bioproject PRJNA601153. Code for analyses and ASV tables with taxonomy, sequence count, and raw metadata used for this project are available at https://github.com/maracashay/Sorghum-RhizosphereChopraBruns. Full descriptions of the methods and analyses can be found in Supplementary File S1.

\section{RESULTS}

Root chemical concentrations change after frost and between lines. Results from the linear mixed-effects models indicated that all variables were affected by time (frost), while DPPH was affected by line, and luteolinidin and total flavonoid concentrations were influenced by the interaction between time and line (Supplementary Table S2). Mean concentrations for all lines before and after frost can be found in Supplementary Table S3). Mean activity of DPPH before frost were 0.256 (standard error [SE] 0.02) and 0.300 (SE 0.02) $\mathrm{TE} \mathrm{mg} \mathrm{g}^{-1}$ after frost, while total phenolic concentrations before frost were 4.62 (SE 0.37) and 2.77 (SE 0.26) $\mathrm{mg} \mathrm{g}^{-1}$ after frost. Assessment of DPPH activity by line indicated higher activity in line N326 compared with N334, with mean activities of 0.35 (SE 0.01 ) and 0.20 (SE 0.01) $\mathrm{mg} \mathrm{g}^{-1}$, respectively.

Analysis of luteolinidin ( $\log 10 \mathrm{mg} \mathrm{g}^{-1}$ root) by line-time indicated that the lines N321 (mean of -0.94 SE 0.02) and N326 (mean of -0.940 SE 0.16 ) had significantly lower concentrations than the producer lines and induced line (means between -0.14 and $0.40 \mathrm{mg} \mathrm{g}^{-1}$ ) (Fig. 1A). After frost, N326 (mean of -0.22 SE 0.07) had lower concentrations of luteolinidin compared with N336 and N337 (means of 0.43 SE 0.12 and 0.29 SE 0.06, respectively) (Fig. 1A). Lines N321, N326, and N336 had increased concentrations of luteolinidin after frost compared with before frost (Fig. 1A).

Concentrations of total flavonoids were also different between lines and time. Line N321 had lower total flavonoids (mean of -0.29 SE 0.12) compared with the producer lines and induced line before frost (means between 0.07 and 0.30) (Fig. 1B). Line N326 (mean of -0.12 SE 0.01 ) was also lower than N334 (mean of 0.30 SE 0.10) before frost (Fig. 1B). After frost, concentrations of total flavonoids were lower in the nonproducer lines N321 and N326 (means of -0.56 SE 0.03 and -0.68 SE 0.09 , respectively) and one producer line N336 (mean of -0.55 SE 0.07) compared with the producer line $\mathrm{N} 334$ (mean of $-0.17 \mathrm{SE} 0.01$ ) and the induced line N337 (mean of -0.21 SE 0.01) (Fig. 1B). All five lines had lower total flavonoid concentrations after frost compared with before frost (Fig. 1B).

Sequencing overview. In total, 6,088 ASVs were identified from $16 \mathrm{~S}$ rRNA sequencing; of these, 17 were not assigned to the kingdom's Bacteria or Archaea and were subsequently removed. After quality filtering and processing of ITS sequences, approximately 913 ASVs were identified and all were assigned to the kingdom Fungi. Bacterial (16S rRNA gene) reads ranged from 20,244 to 124,359 per sample, with a mean sequence count of 58,008 reads. Two fungal samples had to be removed due to low sequence count (count of 0). Fungal ITS reads ranged from 38,744 to 334,410 per sample, with a mean sample count of 144,707 reads. Each sample was normalized via rarefication for $\alpha$-diversity estimates. Bacterial samples were rarefied to a depth of 20,000 and fungal samples were rarefied to a depth of 38,000 sequences per sample.

Communities change with time and between the lines. $\alpha$ and $\beta$ Diversity. Both richness and Shannon diversity differed between time points for bacterial rRNA datasets but not across line or line-time. No differences in richness or Shannon diversity were observed for fungal ITS datasets (Supplementary Table S4; $P<$ 0.05). Before frost, bacterial communities had a mean richness of 879 (SE 47) and a mean Shannon Diversity of 5.25 (SE 0.10), which were higher than richness and Shannon Diversity after frost, with means of 587 (SE 32) and 4.60 (SE 0.18), respectively. Frost also had a significant impact on the $\beta$ diversity of both the bacterial and fungal communities (Table $1 ; P<0.05$ ). Only fungal diversity was different across sorghum lines (Table $1 ; P<0.05$ ), and results from the pairwise PERMANOVAs indicated differences in fungal ITS sequence composition between N326 and all other lines. The two lines classified as non-3-DA-producers (N321 and N326) had a different ITS composition compared with N334, a line classified as a 3-DA-producer (adjusted $P<0.05$ ).

Differential abundance. Comparisons of rhizosphere samples before and after frost revealed a large shift in community composition for both bacteria and fungi (Table 1; Supplementary Fig. $\mathrm{S} 1$ ). Over half of the bacterial phyla showed significant changes in abundance based on differential abundance analyses (Supplementary Table S5). At the class level, 27.2 and $45.4 \%$ of bacterial and fungal taxa, respectively, were differentially abundant (Supplementary Table S5). These changes decreased at lower taxonomic levels but were still quite high, with 26 and $21.1 \%$ of bacterial and 
fungal genera, respectively, being differentially abundant before and after frost.

Few bacterial taxa were differentially abundant across lines (Supplementary Table S6). Of 6,061 total bacterial and archaeal ASVs, only 7 to 13 ASVs differed across lines. Of 488 prokaryotic genera detected, no more than 4 differed across lines. No bacterial or archaeal taxa above genus level differed in abundances across lines. In contrast, many fungal taxa were differentially abundant across lines, ranging from 30 to $90 \mathrm{ASVs}$ and accounting for 3.3 to $9.8 \%$ of all ASVs (Supplementary Table S6). Fungal taxa at higher taxonomic classifications were also found to be differentially abundant across lines, except at the phylum level.
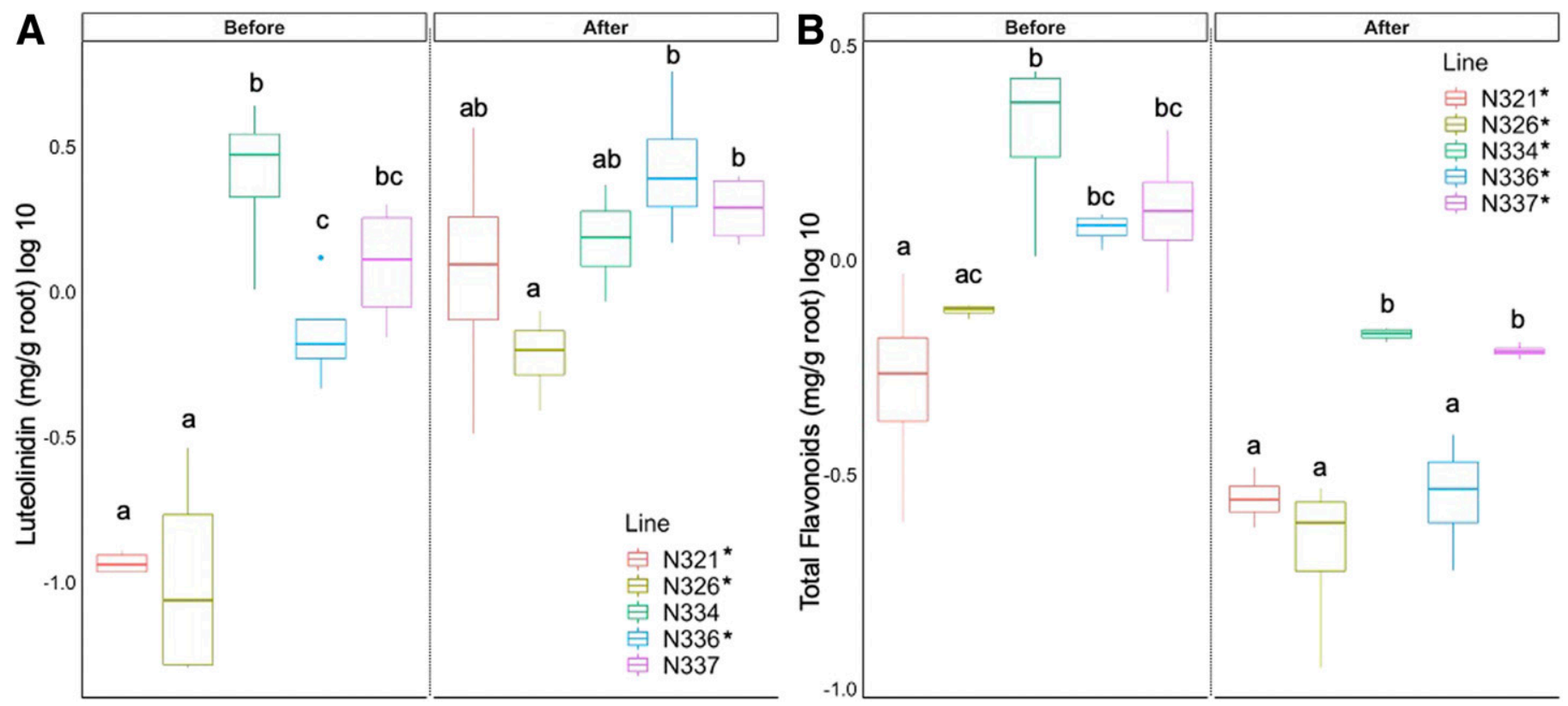

Fig. 1. Root chemical concentrations across line-time for A, luteolinidin and $\mathbf{B}$, total flavonoids. Values are expressed in milligrams per gram of root and transformed using log10 to meet linear mixed-effects modeling assumptions. Letters and asterisks denote differences between lines and time identified through emmeans with Tukey $P$ value adjustments. Lowercase letters indicate significant differences between lines for Before and After sampling times (adjusted $P<0.05$ ). Asterisks next to lines indicate significant differences between luteolinidin or total flavonoid root concentrations between the Before and After samples (adjusted $P<0.05$ ).

TABLE 1

Community composition for the internal transcribed spacer (ITS) region and 16S ribosomal RNA gene sequences using Bray-Curtis or weighted UniFrac ${ }^{\mathrm{a}}$

\begin{tabular}{|c|c|c|c|c|c|c|}
\hline wUniFrac & Sum of squares & Mean squares & DF & $F$ value & $R^{2}$ & $\operatorname{Pr}(>F)$ \\
\hline \multicolumn{7}{|l|}{$16 S$} \\
\hline Line & 0.046 & 0.011 & 4 & 1.451 & 0.101 & 0.134 \\
\hline Line-time & 0.033 & 0.008 & 4 & 1.032 & 0.072 & 0.414 \\
\hline Residuals & 0.236 & 0.008 & 30 & $\ldots$ & $\ldots$ & $\ldots$ \\
\hline Time & 1.704 & 1.704 & 1 & 10.473 & 0.215 & $<0.001^{*}$ \\
\hline Line-time & 0.646 & 0.162 & 4 & 0.993 & 0.081 & 0.481 \\
\hline Residuals & 7.944 & 0.163 & 30 & $\ldots$ & $\ldots$ & $\ldots$ \\
\hline \multicolumn{7}{|l|}{ ITS } \\
\hline Line-time & 0.484 & 0.121 & 4 & 1.005 & 0.083 & 0.457 \\
\hline Residuals & 3.371 & 0.120 & 28 & $\ldots$ & $\ldots$ & $\ldots$ \\
\hline
\end{tabular}


In several cases, patterns of differential abundance across sorghum lines did emerge for some bacterial and fungal genus-level assignments (Table 2). For example, the bacterial genera Delftia, Rhodoferax, and Methylorosula had different abundances in the nonproducer lines (N321 and N326) compared with the 3-DA producer line, N336. Genus Comamonas was higher in N321 and N326 compared with producer lines N334 and N336, as well as the induced line N337 (Table 2). Abundance of the genus Fusarium was higher in the nonproducer line N326 compared with the producer lines and the induced line. The 3-DA-producing line N334 supported lower numbers of both the fungal genus Corynespora and the bacterial genus Rosenbergiella in the rhizosphere compared with all other lines (Table 2). Genera Sporobolomyces and Acephala had exactly opposite abundance patterns, where Sporobolomyces was lower in the nonproducer N321 and in the producer line N336 compared with the three other lines. The genus Acephala was higher in N321 and N336 compared with the other three lines (Table 2).

Differential abundances of ASVs from bacterial and fungal communities were observed when comparing producer lines (N334 and N336) with nonproducer lines (N321 and N326) and are shown in Figures 2 and 3. Of the four bacterial ASVs that were differentially abundant between the producer and nonproducer lines, three were higher in the nonproducers and belonged to the family Pseudomonadaceae. Producer rhizospheres had a higher abundance of one ASV that was assigned to the genus Chujaibacter (Fig. 2).

In contrast to the four bacterial ASVs that were differentially abundant between producer and nonproducer lines, 27 fungal ASVs were differentially abundant (Fig. 3). Rhizosphere communities of 3-DA producers had 18 ASVs that were more abundant and 9 ASVs that were less abundant compared with nonproducer communities. Approximately 18 of the 27 fungal ASVs belonged to genera Mortierella, Septophoma, or Fusarium (Fig. 3). Interestingly, some Mortierella and Fusarium ASVs were higher in producers, whereas other ASVs from these genera were higher in the nonproducers. In contrast, all ASVs assigned to Setophoma were higher in the producer lines (Fig. 3).

Communities and root chemistry relationships. Community diversity. Mantel tests were performed to assess correlations between dissimilarities in rhizosphere community compositions and root contents of total flavonoids, luteolinidin, and total phenolics (Table 3; $P<0.05$ ). Correlations between bacterial composition and root chemicals were highest when Bray-Curtis dissimilarity was assessed by total flavonoid with an $\mathrm{Mr}$ value of 28.2 and a $P=0.001$ (Table 3). When all variables were included (total flavonoid + total phenolics + DPPH + luteolinidin), the Mr value was slightly lower at 26.5 but still significant for Bray-Curtis. Correlations between phylogenetic distances (weighted UniFrac) and root chemical variables were slightly lower compared with Bray-Curtis correlations for 16S rRNA gene communities (Table 3 ). Fungal community dissimilarity based on Bray-Curtis was only correlated to total flavonoids $(\mathrm{Mr}$ of 16.9 and $P=$ 0.013 ) and all variables $(\mathrm{Mr}$ of 12.1 and $P=0.049$ ) (Table 3). Fungal community dissimilarities were not correlated to luteolinidin or total phenolics because the bacterial dissimilarities were correlated.

TABLE 2

Genera identified from the $16 \mathrm{~S}$ and internal transcribed spacer (ITS) datasets that are differentially abundant among sorghum lines (DESeq analyses; adjusted $P<0.05)^{\mathrm{a}}$

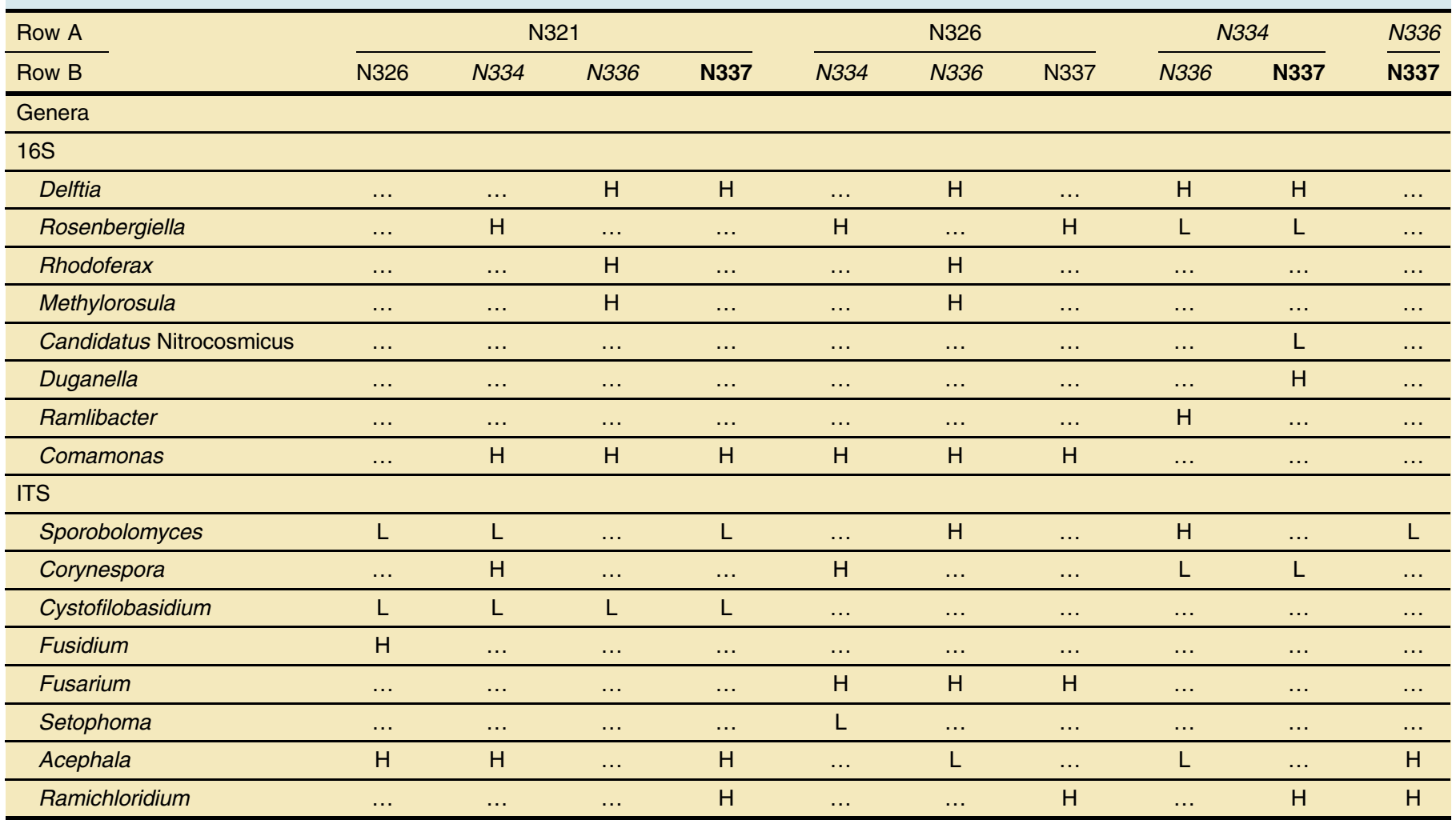

a Symbols: $\mathrm{H}$ in columns indicates that the genus is higher in the line shown in row $A$ compared with the line shown in row $B$, and $L$ in columns indicates that the genus is lower in the row A line than in the row B line. Nonproducer lines are designated in roman, producer lines in italics, and the induced line in bold. 
Individual taxon correlations. Abundances of very few fungal taxa were correlated with root chemical variables, whereas abundances of many bacterial taxa were correlated (Table 4). Only three and two fungal ASVs were correlated with total flavonoids in the producer and luteolinidin and total phenolics in the nonproducer lines (Table 4). When assessing correlations between bacterial taxa associated with the producer and nonproducer lines separately, 18 ASVs were found to be correlated with total flavonoids in the 3-DA producers and $52 \mathrm{ASV}$ s were correlated with luteolinidin in the nonproducers. Associations between luteolinidin, total flavonoids, total phenolics, and bacterial taxon abundances were observed from ASV to phylum level (Table 4).

Several bacterial taxa were associated with both total flavonoids from producer lines and luteolinidin from nonproducer lines, and these overlaps were identified from ASVs through phyla (Fig. 4; Supplementary Fig. S2). At the genus level, 15 genera were shared between 3-DA-producer and nonproducer lines and included Asticcaacaulis, 'Candidatus Ovatusbacter', Cytophaga, Dyadobacter, Ellin6067, Luteimonas, Luteolibacter, Methylotenera, Niastella, Porphyrobacter, Ramlibacter, Reyranella, Sphingomonas, Thermomonas, and the Burkholderia/Caballeronia/Paraburkholderia group. Interestingly, the type of correlation was the opposite between luteolinidin and total flavonoids; all correlations with luteolinidin were negative and nearly all of the correlations with total flavonoids were positive. At the genus level, all 33 genera were negatively correlated with luteolinidin in the nonproducers, whereas 19 of the 20 genera correlated with total flavonoids were positively correlated in the 3-DA-producer lines. Phyla that were positively correlated with total flavonoids in the producer lines and negatively correlated with luteolinidin from the nonproducer lines included Acidobacteria, Armatimonadetes, and Bacteroides (Fig. 4).

\section{DISCUSSION}

Frost stress affects sorghum cultivar root chemistry. This study was designed to determine whether frost stress affected sorghum cultivar root chemistry and whether changes to root chemical dynamics had an impact on rhizosphere microbial

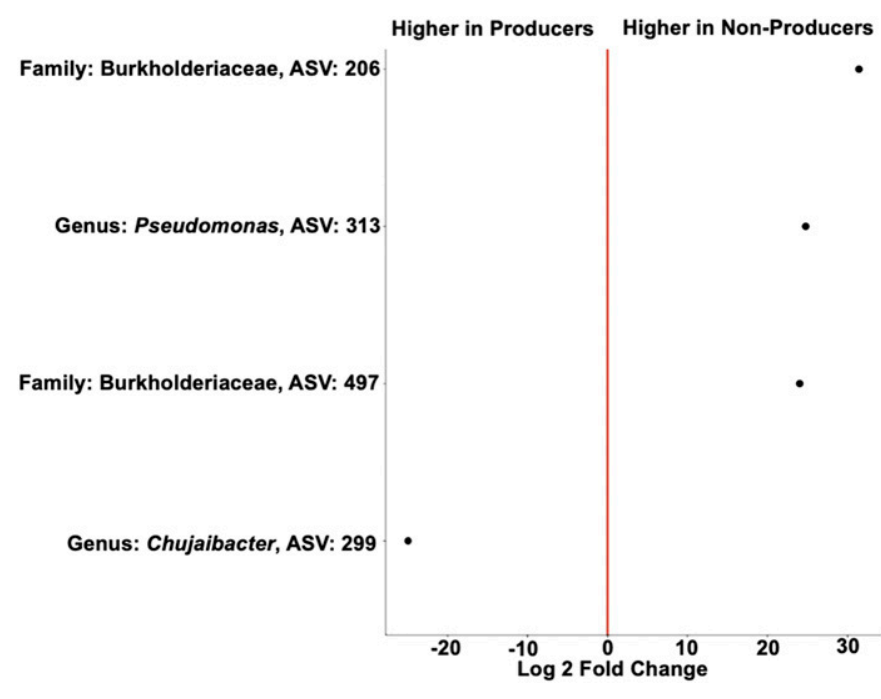

Fig. 2. Differentially abundant $16 \mathrm{~S}$ ribosomal RNA gene amplicon sequence variants (ASVs) between producer and nonproducer lines (DESeq analyses; adjusted $P<0.05$ ). Taxonomic classifications of ASVs are provided. communities. In earlier studies, 3-DA production by sorghum was assessed for phytoalexin activity, because 3-DAs are produced and translocated at the sites of fungal infection in sorghum foliar tissues (Nielsen et al. 2004; Snyder et al. 1991). Biosynthesis of 3-DAs has also been hypothesized to be due to abiotic stresses and root exudation patterns can change in response to stress, including both abiotic and biotic stresses (Canarini et al. 2019; Edayilam et al. 2018; Gargallo-Garriga et al. 2018). Herein, we did find increased concentrations of luteolinidin, a compound within the 3-DA class of flavonoids, after frost but this change was dependent on the specific S. bicolor line analyzed (Fig. 1). In a study comparing irrigation treatments, 3-DA production was found to be highest in sorghum grain grown under drought stress (Wu et al. 2017). However, we also found decreases in total flavonoids and total phenolics after frost, which supports the findings of Sheflin et al. (2019). In their study, concentrations of phenylalanine, a precursor molecule of flavonoids, 3-DAs, and other defense compounds such as salicylic acid, were lower in sorghum roots grown under nitrogen stress. Lower concentrations of 3-DA precursor molecules after a stress event may indicate that these molecules have, in fact, been synthesized to 3-DA compounds. Changes in flavonoid exudation patterns can affect a plant's ability to attract rhizobia or fungi, and these can shape rhizosphere communities by acting as either a carbon source or a toxic compound for certain groups of microorganisms (Broeckling et al. 2008; Shaw et al. 2006). Further understanding of how root exudation patterns change in response to stress and how those patterns relate to plant health is important for determining how climate change will affect sorghum crop yield and grain quality.

Rhizosphere microbial communities affected by frost. Plant stress in the form of frost not only affects root exudation patterns of plants, as previously mentioned, but can also directly affect soil microorganisms' physiology by slowing metabolisms and disrupting cell membranes (Schimel et al. 2007). Microbial biomass and respiration decrease during repeated freeze-thaw cycles by 33.3 and 30\%, respectively (Larsen et al. 2002; Pesaro et al. 2003; Schimel and Clein 1996). Studies have proposed a communitywide shift toward bacterial dominance following freeze-thaw (Nieminen and Setala 2001; Larsen et al. 2002). Although we did not determine the ratios of bacteria/fungi in these rhizosphere communities, we did determine that bacterial but not fungal diversity decreased following frost. Frost affected bacterial composition more strongly ( $R^{2}=21.5$ for Bray-Curtis and $R^{2}=30.5$ for wUniFrac) than fungal composition $\left(R^{2}=13.8\right)$ (Table 1$)$. Considering the broad-level changes to both bacterial and fungal taxa $(27 \%+$ at class level) before and after frost, it is clear that frost has a significant impact on rhizosphere microbial communities (Supplementary Table S5; Supplementary Fig. S1). However, because frost also affected root exudation patterns, we cannot rule out the possibility that frost had an indirect effect on rhizosphere communities or some combination of direct and indirect effects.

Differences in microbiome diversity between sorghum lines. In a study by Schlemper et al. (2018), a significant interaction was observed between sorghum line and soil type that drove differences in bacterial but not fungal communities. Other studies have also observed effects of soil type on sorghum bacterial rhizosphere community compositions (Marschner et al. 2004; Oberholster et al. 2018), which may be exacerbated in the earlier stages of sorghum growth (Schlemper et al. 2017). We had originally hypothesized that the rhizosphere communities for bacterial and fungal communities would be distinct between the nonproducing, producing, and induced lines. However, no differences were observed for $\alpha$-diversity metrics across lines and there were no interactive effects of line-time (Supplementary Table S4). We also found no 
differences in bacterial community composition across lines but there was a significant difference in fungal composition (Table 1). Bacterial community composition has been suggested to be less sensitive to specific cultivars and more sensitive to environmental variables such as the amount of $\mathrm{NH}_{4}^{+}, \mathrm{NO}_{3}^{-}$, and carbon, and soil texture (Ramond et al. 2013). In contrast to our experiment and the experiment by Ramond et al. (2013), Schlemper et al. (2017) did find cultivar-driven bacterial rhizosphere community composition when studying Striga-resistant sorghum cultivars. Because the sorghum cultivars used in this study were NILs, it may be that these plant genotypes are not different enough to elicit largeenough changes in bacterial communities; however, fungal communities may be more sensitive to small changes in plant genotypes.

More important than overall differences in community structure across cultivars may be changes in individual taxa or lineages of taxa between the cultivars. Several taxa that may be important in promoting plant growth, suppressing pathogenic microbes, or nutrient cycling in these sorghum rhizospheres were identified as being differentially abundant across lines or between the producer and nonproducer lines (Table 2; Figs. 2 and 3). These include 'Candidatus Nitrocosmicus', Chujaibacter, Comamonas, Delftia,
Duganella, Pseudomonas, Ramlibacter, Rhodoferax, Corynespora, Fusarium, Fusidium, Hymenoscyphus, Mortierella, and Setophoma terrestris.

Bacteria belonging to the genus Pseudomonas were found to be higher in the nonproducer lines compared with the producer lines (Fig. 2). In other studies, some members of the genus Pseudomonas can be pathogenic to sorghum, while others can directly increase sorghum yield or produce compounds that inhibit the growth of soilborne plant pathogens (Capper and Higgins 1993; Sajeli Begym et al. 2014; Vidhyasekaran and Muthamilan 1995; Weller 2007). Genus Ramlibacter has also been implicated as suppressing soilborne diseases for sweet pepper (L.-N. Zhang et al. 2019) and was found to be significantly lower in the induced line compared with the producer line, N334. Although not specific to sorghum, other genera, including Comamonas, Delftia, and Dunganella, have all either been identified as potentially plant-growth promoting through the production of compounds like indole-acetic acid (Tsolakidou et al. 2019; Zhang et al. 2016) or correlated with the availability of nutrients like N, P, and S (Schmalenberger et al. 2008; Tang et al. 2019; Tayyaba and Muhammad 2015; L.-N. Zhang et al. 2019). Both Comamonas and Delftia were higher in the nonproducer lines compared with the producer line, N336, while Duganella was

Species: Fusarium acutatum, ASV279.

Species: Fusarium acutatum, ASV245

Species: Fusarium acutatum, ASV156

Species: Fusarium acutatum, ASV244

Family: Mortierellaceae, ASV157

Species: Fusarium acutatum, ASV194.

Species: Corynespora cassiicola, ASV292

Genus: Mortierella, ASV94

Species: Fusarium solani, ASV65.

Species: Setophoma terrestris, ASV276

Genus: Mortierella, ASV116

Species: Setophoma terrestris, ASV215

Species: Setophoma terrestris, ASV363.

Order: Pleosporales, ASV338.

Species: Botrytis cinerea, ASV240.

Genus: Tetraplosphaeria, ASV158.

Species: Fusarium culmorum, ASV219.

Species: Cladosporium delicatulum, ASV230.

Species: Setophoma terrestris, ASV141

Species: Mortierella minutissima, ASV171.

Order: Pleosporales, ASV163

Genus: Mortierella, ASV118.

Genus: Mortierella, ASV205

Species: Setophoma terrestris, ASV85

Order: Pleosporales, ASV64

Genus: Acephala, ASV197.

Genus: Mortierella, ASV184

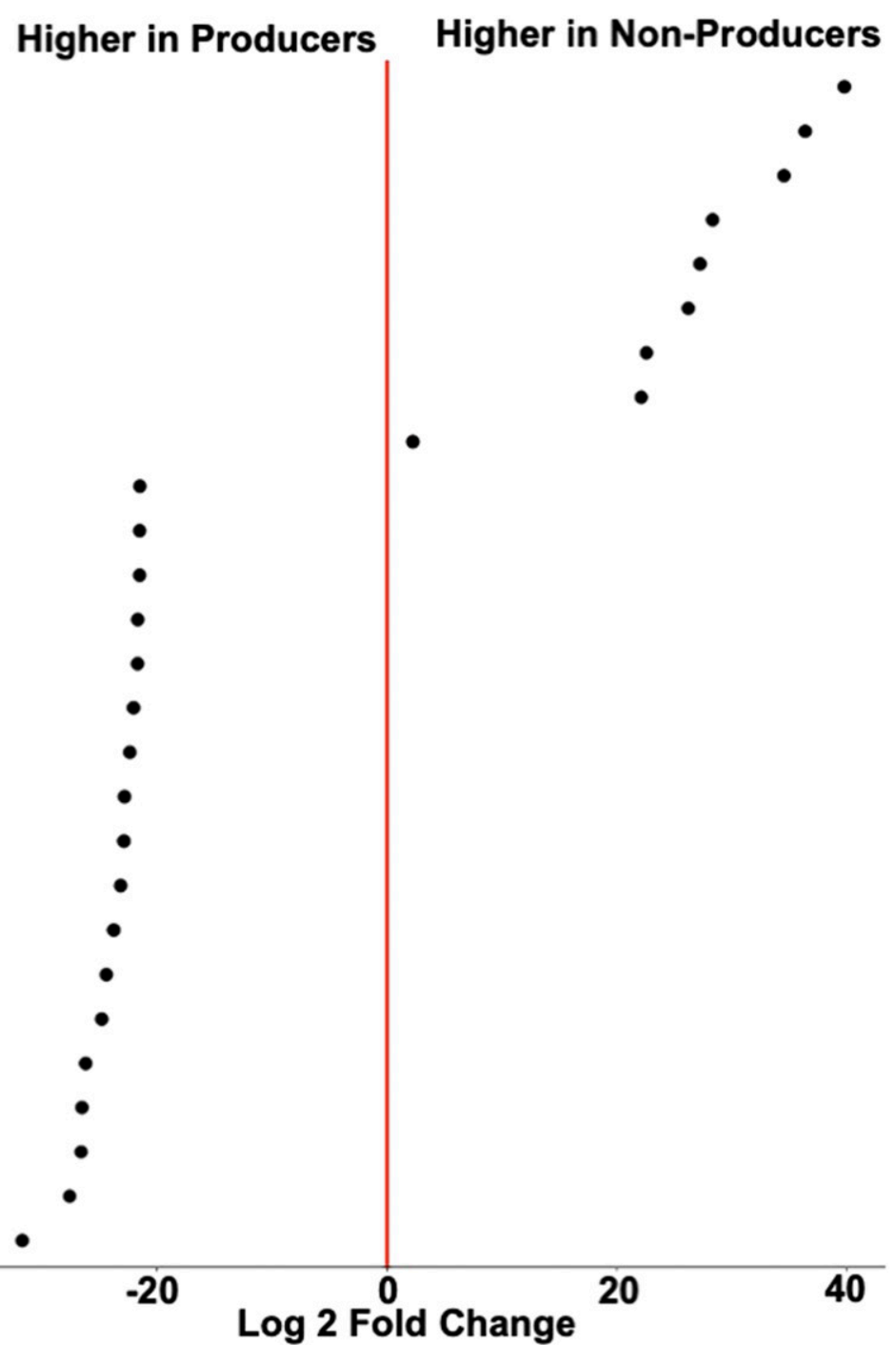

Fig. 3. Differentially abundant internal transcribed spacer amplicon sequence variants (ASVs) between producer and nonproducer lines (DESeq analyses; adjusted $P<0.05$ ). Taxonomic classifications of ASVs are provided. 
significantly lower in the induced line, N337, compared with the producer line, N334 (Table 2). Two other genera that might also be important for controlling the availability of nitrogen that have differential abundances between the lines include ' $C a$. Nitrocosmicus' and Chujaibacter, which have been associated with nitrogen cycling reactions, including ammonia oxidation and nitrification, respectively (Alves et al. 2019; Kong et al. 2019; Lehtovirta-Morley et al. 2016; Rodriguez-Sanchez et al. 2018; Sauder et al. 2017).

Of the fungal taxa that were identified as being differentially abundant across the lines or between producer and nonproducer lines, several have plant-growth-promoting properties or could be used as biocontrol inoculants. Mortierella spp. can solubilize phosphorous and are often found associated with rhizospheres of plants (Gkarmiri et al. 2017; Qiao et al. 2019; Zhang et al. 2011; T. Zhang et al. 2019). Several ASVs assigned to Mortierella were differentially abundant in the producer lines, while other Mortierella ASVs were higher in the nonproducer lines (Fig. 3). Species within the fungal genus Fusidium produce an antibiotic (fusidic acid) and an antifungal compound (fusidilactone) and are known to be endophytes of plants (Godtfredsen et al. 1962; Gunatilaka 2006). Herein, the genus Fusidium was more abundant in line N321 compared with line N326, both of which are nonproducers (Table 2).

There were four fungi identified as being differentially abundant that were assigned to taxa known to be pathogenic to plants: $B o-$ trytis cinerea, Corynespora sp., Fusarium sp., and Setophoma terrestris. Of these fungi, only Fusarium has been identified as a potential pathogen of sorghum, causing stalk rot, grain mold, and seedling blight of sorghum (Castor and Frederiksen 1980; Frederiksen 1986; Jardine and Leslie 1992; Petrovic et al. 2009; Reed et al. 1983). Although we did not see any evidence of disease on the sorghum, it is interesting to note the differences in abundance across the sorghum lines. Sorghum line N326 had a higher abundance of Fusarium compared with N334, N336, and N337 (Table 2); six Fusarium ASVs were more abundant in the nonproducers and one was more abundant in the producer lines (Fig. 3). Genera Botrytis and Corynespora and Setophoma terrestris cause diseases in other crops such as canola, cucumber, cotton, onion, soybean, squash, and tomato (Hansen 1929; Ikeda et al. 2012;

TABLE 3

EcoDist (Mantel test) results correlating dissimilarity of environmental variables (Euclidean) to dissimilarity in community composition for $16 \mathrm{~S}$ and internal transcribed spacer (ITS) sequences (Bray-Curtis or weighted UniFrac) ${ }^{\mathrm{a}}$

\begin{tabular}{|c|c|c|c|c|c|c|c|c|c|c|}
\hline \multirow[b]{2}{*}{ Sequence } & \multicolumn{2}{|c|}{ All variables } & \multicolumn{2}{|c|}{ Total flav ${ }^{b}$} & \multicolumn{2}{|c|}{ Luteolinidin } & \multicolumn{2}{|c|}{ Total phenolics } & \multicolumn{2}{|c|}{$\mathrm{DPPH}^{\mathrm{c}}$} \\
\hline & $\mathrm{Mr}$ & $P$ & $\mathrm{Mr}$ & $P$ & $\mathrm{Mr}$ & $P$ & $\mathrm{Mr}$ & $P$ & $\mathrm{Mr}$ & $P$ \\
\hline Bray-16S & 26.5 & $0.001^{*}$ & 28.2 & $0.001^{*}$ & 20.9 & $0.001^{*}$ & 14.0 & $0.004^{*}$ & 0.9 & 0.417 \\
\hline Bray-ITS & 12.1 & $0.049^{*}$ & 16.9 & $0.013^{*}$ & 7.4 & 0.120 & 10.8 & 0.350 & 1.8 & 0.59 \\
\hline
\end{tabular}

a Significant correlations are denoted with an asterisk $\left(^{*}\right)(P<0.05)$.

b Total flavonoids.

c $\mathrm{DPPH}=$ 2,20-diphenyl-1-picrylhydrazyl.

TABLE 4

Number of Kendall correlations between $16 \mathrm{~S}$ or internal transcribed spacer (ITS) taxa abundances and root chemical concentrations and 2,20-diphenyl-1-picrylhydrazyl (DPPH) activity that were $\geq 0.50$ or $\leq-0.5^{\mathrm{a}}$

\begin{tabular}{|c|c|c|c|c|c|c|c|c|c|c|c|c|}
\hline \multirow[b]{2}{*}{ Group } & \multicolumn{4}{|c|}{ All five lines } & \multicolumn{4}{|c|}{ Producers } & \multicolumn{4}{|c|}{ Nonproducers } \\
\hline & Flav & Lute & Phen & DPPH & Flav & Lute & Phen & DPPH & Flav & Lute & Phen & DPPH \\
\hline \multicolumn{13}{|l|}{$16 S$} \\
\hline Genera & 1 & 0 & 1 & 0 & 20 & 0 & 9 & 0 & 9 & 33 & 17 & 2 \\
\hline Families & 0 & 0 & 0 & 0 & 17 & 0 & 7 & 0 & 10 & 24 & 14 & 1 \\
\hline Phyla & 0 & 0 & 0 & 0 & 4 & 0 & 3 & 0 & 2 & 4 & 3 & 0 \\
\hline \multicolumn{13}{|l|}{ ITS } \\
\hline ASVs & 0 & 0 & 0 & 0 & 3 & 0 & 0 & 0 & 0 & 2 & 2 & 0 \\
\hline Genera & 0 & 0 & 0 & 0 & 2 & 0 & 0 & 0 & 0 & 2 & 1 & 0 \\
\hline Phyla & 0 & 0 & 0 & 0 & 0 & 0 & 0 & 0 & 0 & 0 & 0 & 0 \\
\hline
\end{tabular}

a Flav = total flavonoids, Lute = luteolinidin, Phen = total phenolics, and ASVs = amplicon sequence variants. 
MacKenzie et al. 2018; Prins et al. 2000; Yang et al. 2017; F. B. Zhang et al. 2019). Nonproducer lines had higher abundances of six ASVs assigned to Fusarium spp. and one ASV assigned to Corynespora cassiicola (Fig. 3). In contrast, producer lines had higher abundances of five ASVs assigned to $S$. terrestris, one ASV assigned to B. cinera, and one ASV assigned to Fusarium culmorum (Fig. 3). It is unclear why the abundances of these pathogenic fungi (not to sorghum) are different between producer and nonproducer lines. Further exploration of activity and function of these plant-fungal rhizosphere interactions should be performed to determine how these lines of sorghum are influencing fungal communities in soils.

Root chemistry and sorghum rhizosphere microbial communities. Cultivar-dependent exudation patterns from sorghum roots have been suggested to influence rhizosphere microbial community composition (Funnell-Harris et al. 2008). Studies have observed differences in exudation patterns of certain compounds, including flavonoids, important for attracting symbiotic fungi and altering plant defense systems (Steinkellner et al. 2007). In this study, we identified correlations between total flavonoids and luteolinidin in sorghum roots and bacterial rhizosphere abundances (Fig. 4). More specifically, bacteria in the rhizospheres of nonproducers were negatively affected by luteolinidin, which indicates that luteolinidin may have an antibacterial effect. Correlations between bacteria and total flavonoids of producers were almost entirely positive. Because luteolinidin is a flavonoid compound, and luteolinidin and total flavonoids had an opposite effect on bacterial abundances, we cannot rule out the possibility that other metabolites produced by sorghum may be driving some of the differences in rhizosphere community compositions across these sorghum lines.

Conclusion. In this study, root concentrations in Sorghum bicolor of luteolinidin and total flavonoids were different not only after frost but were also different between the NILs. Rhizosphere microbial communities were different before and after frost, leading us to hypothesize that frost did affect microbial communities; however, it is unclear whether this was a direct or indirect effect. Fungal communities and individual taxon abundances were different between sorghum lines, while relatively few bacterial taxa were different between sorghum lines. In contrast, abundances of bacteria rather than fungi were sensitive to root chemical variables, specifically total flavonoids, and luteolinidin. Taxa from the nonproducer lines were negatively affected by luteolinidin, while taxa from the producer lines were positively correlated with total flavonoids. These findings have important implications for understanding plant-microbe interactions and how sorghum rhizosphere communities differ between NILs. Many taxa that were differentially abundant across lines have been implicated as plant-growth promoters, potential biocontrols for soilborne diseases, or plant pathogens. Future studies should incorporate activity or functional analyses of microbial communities and plant gene expression analyses to elucidate how the production of root chemicals by sorghum influences rhizosphere communities.
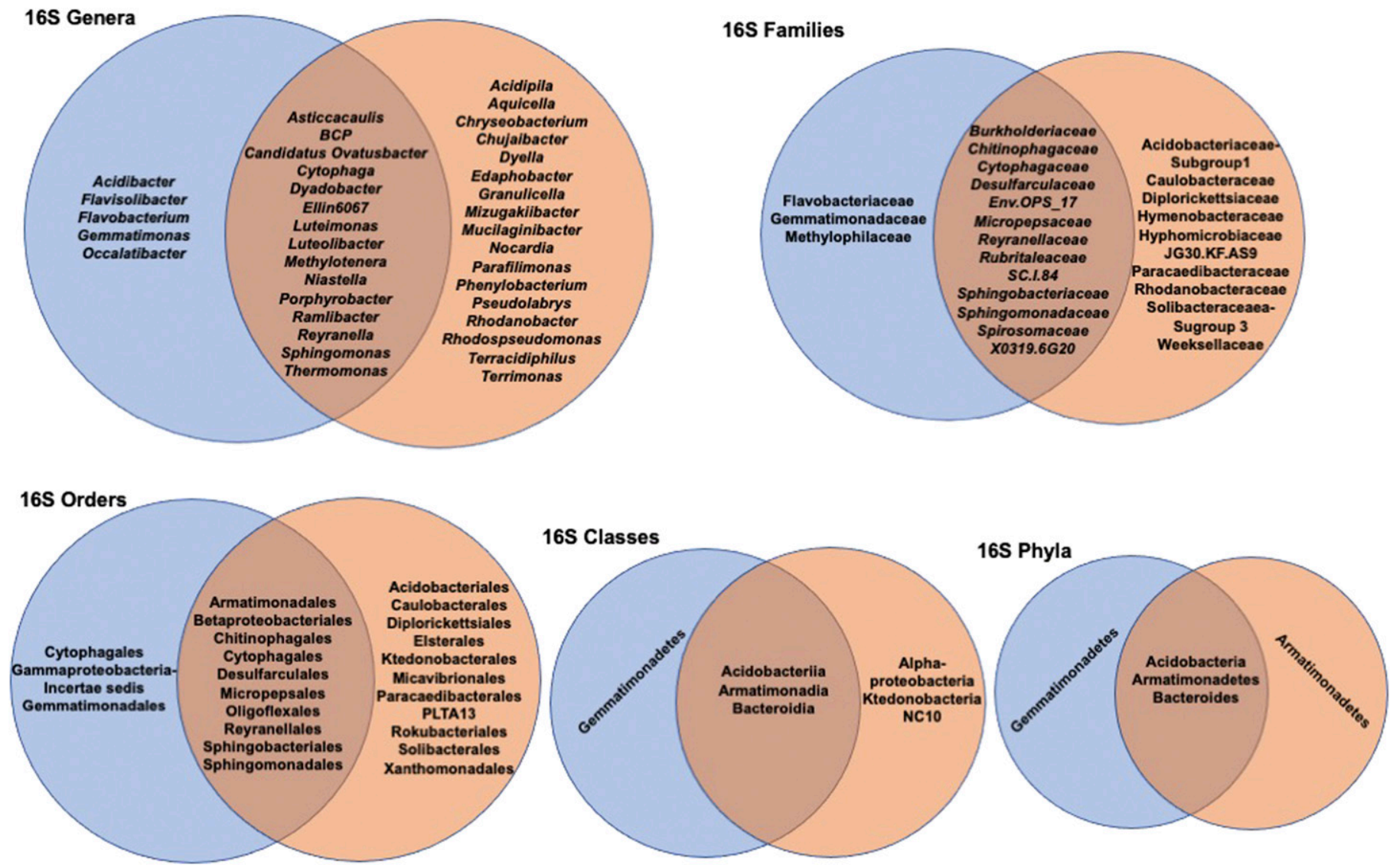

Fig. 4. Venn diagrams showing the taxa correlated with total flavonoids in the producer lines (blue) and luteolinidin in the nonproducer lines (orange). Taxa included in the overlapping area are those that are correlated with both total flavonoids in the producer lines and luteolinidin in the nonproducer lines. Correlations were calculated using Kendall correlations and only correlations $\leq 0.50$ or $\leq-0.5$ between taxa and total flavonoids and luteolinidin are represented. 


\section{ACKNOWLEDGMENTS}

We thank J. Pedersen and J. Toy, Grain, Forage \& Bioenergy Research, USDA-ARS, Lincoln, NE for providing seed of sorghum lines; S. Harkcom and Agronomy farm staff for field management assistance; and J. Prusch and T. Alcaide for help with plant excavations and sample collections.

\section{LITERATURE CITED}

Abdel-Lateif, K., Bogusz, D., and Hocher, V. 2012. The role of flavonoids in the establishment of plant roots endosymbiosis with arbuscular mycorrhiza fungi, rhizobia and Frankia bacteria. Plant Signal. Behav. 7: 636-641.

Alves, R. J. E., Kerou, M., Zappe, A., Bittner, R., Abby, S. S., Schmidt, H. A., Pfeifer, K., and Schleper, C. 2019. Ammonia oxidation by the arctic terrestrial Thaumarchaeote Candidatus Nitrosocosmicus arcticus is stimulated by increasing temperatures. Front. Microbiol. 10:1571.

Baerson, S. R., Dayan, F. E., Rimando, A. M., Dhammika Nanayakkara, N. P., Liu, C.-J., Schröder, J., Fishbein, M., Pan, Z., Kagan, I. A., Pratt, L. H., Cordonnier-Pratt, M.-M., and Duke, S. O. 2007. A functional genomics investigation of allelochemical biosynthesis in Sorghum bicolor root hairs. J. Biol. Chem. 283:3231-3247.

Boddu, J., Svabek, C., Ibraheem, F., Jones, A. D., and Chopra, S. 2005. Characterization of a deletion allele of a sorghum Myb gene yellow seed 1 showing loss of 3-deoxyflavonoids. Plant Sci. 169:542-552.

Broeckling, C. D., Broz, A. K., Bergelson, J., Manter, D. K., and Vivanco, J. M. 2008. Root exudates regulate soil fungal community composition and diversity. Appl. Environ. Microbiol. 74:738-744.

Callahan, B. J., McMurdie, P. J., Rosen, M. J., Han, A. W., Johnson, A. J. A., and Holmes, S. P. 2016. DADA2: High-resolution sample inference from Illumina amplicon data. Nat. Methods 13:581-583.

Canarini, A., Kaiser, C., Merchant, A., Richter, A., and Wanek, W. 2019. Root exudation of primary metabolites: Mechanisms and their roles in plant responses to environmental stimuli. Front. Plant Sci. 10:157.

Capper, A. L., and Higgins, K. P. 1993. Application of Pseudomonas fluorescens isolates to wheat as potential biological control agents against take-all. Plant Pathol. 42:560-567.

Castor, L. L., and Frederiksen, R. A. 1980. Fusarium and Curvularia grain molds in Texas. Pages 93-102 in: Proc. Int. Workshop Sorghum Dis. Hyderabad, India, December 11-15, 1978. ICRISAT.

Cotton, T. E. A., Pétriacq, P., Cameron, D. D., Meselmani, M. A., Schwarzenbacher, R., Rolfe, S. A., and Ton, J. 2019. Metabolic regulation of the maize rhizobiome by benzoxazinoids. ISME J. 13:1647-1658.

de Vries, F. T., Griffiths, R. I., Knight, C. G., Nicolitch, O., and Williams, A. 2020. Harnessing rhizosphere microbiomes for drought-resilient crop production. Science 368:270-274

Edayilam, N., Montgomery, D., Ferguson, B., Maroli, A. S., Martinez, N., Powell, B. A., and Tharayil, N. 2018. Phosphorous stress-induced changes in plant root exudation could potentially facilitate uranium mobilization from stable mineral forms. Environ. Sci. Technol. 52:7652-7662.

FAOSTAT Statistical Database. Food and Agricultural Organization of the United Nations. Rome, Italy. http://www.fao.org/faostat/en/\#data

Frederiksen, R. A., ed. 1986. Compendium of Sorghum Diseases. American Phytopathological Society, St. Paul, MN, U.S.A.

Funnell-Harris, D. L., Pedersen, J. F., and Marx, D. B. 2008. Effect of sorghum seedlings, and previous crop, on soil fluorescent Pseudomonas spp. Plant Soil 311:173-187.

Gargallo-Garriga, A., Preece, C., Sardans, J., Oravec, M., Urban, O., and Peñuelas, J. 2018. Root exudate metabolomes change under drought and show limited capacity for recovery. Sci. Rep. 8:12696.

Gkarmiri, K., Mahmood, S., Ekblad, A., Alström, S., Högberg, N., and Finlay, R. 2017. Identifying the active microbiome associated with roots and rhizosphere soil of oilseed rape. Appl. Environ. Microbiol. 83: e01938-17.

Godtfredsen, W., Roholt, K., and Tybring, L. 1962. Fucidin: A new orally active antibiotic. Lancet 279:928-931.

Górniak, I., Bartoszewski, R., and Kroliczewski, J. 2019. Comprehensive review of antimicrobial activities of plant flavonoids. Phytochem. Rev. 18: 241-272.

Grotewold, E., Chamberlin, M., Snook, M., Siame, B., Butler, L., Swenson, J., Maddock, S., St. Clair, G., and Bowen, B. 1998. Engineering secondary metabolism in maize cells by ectopic expression of transcription factors. Plant Cell 10:721-740.

Guidi, L., Brunetti, C., Fini, A., Agati, G., Ferrini, F., Gori, A., and Tattini, M. 2016. UV radiation promotes flavonoid biosynthesis, while negatively affecting the biosynthesis and the de-epoxidation of xanthophylls: Consequence for photoprotection? Environ. Exp. Bot. 127:14-25.

Gunatilaka, A. L. 2006. Natural products from plant-associated microorganisms: Distribution, structural diversity, bioactivity, and implications of their occurrence. J. Nat. Prod. 69:509-526.

Guo, Y., Liu, S., Yang, Z., Tian, S., and Sui, N. 2016. Responses of unsaturated fatty acid in membrane lipid and antioxidant enzymes to chilling stress in sweet sorghum (Sorghum bicolor (L.) Moench) seedling. J. Agric. Sci. 8:71-83.

Hagan, A. K., Bowen, K. L., Pegues, M., and Jones, J. 2014. Nitrogen rate and variety impact diseases and yield of sorghum for biofuel. Agron. J. 106: 1205-1211.

Hansen, H. N. 1929. Etiology of the pink-root disease of onions. Phytopathology 19:691-704.

Hervé, M. 2019. RVAideMemoire: Testing and plotting procedures for biostatistics. R package version 0.9-73. https://cran.r-project.org/web/ packages/RVAideMemoire/index.html

Hoffmann, L., and Rooney, W. L. 2014. Accumulation of biomass and compositional change over the growth season for six photoperiod sorghum lines. BioEnergy Res. 7:811-815.

Hu, L., Robert, C. A. M., Cadot, S., Zhang, X., Ye, M., Li, B., Manzo, D., Chervet, N., Steinger, T., van der Heijden, M. G. A., Schlaeppi, K., and Erb, M. 2018. Root exudate metabolites drive plant-soil feedbacks on growth and defense by shaping the rhizosphere microbiota. Nat. Commun. 9: 2738-2750.

Ibraheem, F., Gaffoor, I., and Chopra, S. 2010. Flavonoid phytoalexindependent resistance to anthracnose leaf blight requires a functional yellow seed1 in Sorghum bicolor. Genetics 184:915-926.

Ibraheem, F., Gaffoor, I., Tan, Q., Shyu, C.-R., and Chopra, S. 2015. A sorghum MYB transcription factor induces 3-deoxyanthocyanidins and enhances resistance against leaf blights in maize. Molecules 20:2388-2404.

Ikeda, K., Kuwabara, K., Urushibara, T., Soyai, P., Miki, S., and Shibata, S. 2012. Pink root rot of squash caused by Setophoma terrestris in Japan. J. Gen. Plant Pathol. 78:372-375.

Jardine, D. J., and Leslie, J. F. 1992. Aggressiveness of Gibberella fujikuroi (Fusarium moniliforme) isolates to grain sorghum under greenhouse conditions. Plant Dis. 76:897-900.

Jensen, P. J., Halbrendt, N., Fazio, G., Makalowska, I., Altman, N., Praul, C., Maximova, S. N., Ngugi, H. K., Crassweller, R. M., Travis, J. W., and McNellis, T. W. 2012. Rootstock-regulated gene expression patterns associated with fire blight resistance in apple. BMC Genomics 13:9.

Kawahigashi, H., Kasuga, S., Sawada, Y., Yonemaru, J. I., Ando, T., Kanamori, H., Wu, J., Mizuno, H., Momma, M., Fugimoto, Z., and Hirai, M. Y. 2016. The sorghum gene for leaf color changes upon wounding $(\mathrm{P})$ encodes a flavanone 4-reductase in the 3-deoxyanthocyanidin biosynthesis pathway. G3: Genes Genomes Genet. 6:1439-1447.

Kong, Y., Ling, N., Xue, C., Chen, H., Ruan, Y., Guo, J., Zhu, C., Wang, M., Shen, Q., and Guo, S. 2019. Long-term fertilization regimes change soil nitrification potential by impacting active autotrophic ammonia oxidizers and nitrite oxidizers as assessed by DNA stable isotope probing. Environ. Microbiol. 21:1224-1240.

Larsen, K. S., Jonasson, S., and Michelsen, A. 2002. Repeated freeze-thaw cycles and their effects on biological processes in two arctic ecosystem types. Appl. Soil Ecol. 21:187-195.

Lehtovirta-Morley, L. E., Ross, J., Hink, L., Weber, E. B., Gubry-Rangin, C., Thion, C., Prosser, J. I., and Nicol, G. W. 2016. Isolation of 'Candidatus Nitrosocosmicus franklandus', a novel ureolytic soil archaeal ammonia oxidiser with tolerance to high ammonia concentration. FEMS Microbiol. Ecol. 92:fiw057.

Lenth, R. 2020. emmeans: Estimated marginal means, aka least-squares means. R package version 1.4.5. https://cran.r-project.org/web/packages/emmeans/ index.html

Lo, S.-C. C., and Nicholson, R. L. 1998. Reduction of light-induced anthocyanin accumulation in inoculated sorghum mesocotyls: Implications for a compensatory role in the defense response. Plant Physiol. 116:979-989.

Love, M. I., Huber, W., and Anders, S. 2014. Moderated estimation of fold change and dispersion for RNA-seq data with DESeq2. Genome Biol. 15:550.

MacKenzie, K. J., Sumabat, L. G., Xavier, K. V., and Vallad, G. E. 2018. A review of Corynespora cassicola and its increasing relevance to tomato in Florida. Plant Health Prog. 19:303-309. 
Marschner, P., Crowley, D., and Yang, C. H. 2004. Development of specific rhizosphere bacterial communities in relation to plant species, nutrient, and soil type. Plant Soil 261:199-208.

Maw, M. J. W., Houx, J. H., III, and Fritschi, F. B. 2017. Maize, sweet sorghum, and high biomass sorghum ethanol yield comparison on marginal soils in Midwest US. Biomass Bioenergy 107:164-171.

Miller, S. B., Heuberger, A. L., Broeckling, C. D., and Jahn, C. E. 2019. Nontargeted metabolomics reveals sorghum rhizosphere-associated exudates are influenced by the belowground interaction of substrate and sorghum genotype. Int. J. Mol. Sci. 20:431.

Mizuno, H., Kawahigashi, H., Kawahara, Y., Kanamori, H., Ogata, J., Minami, H., Itoh, T., and Matsumoto, T. 2012. Global transcriptome analysis reveals distinct expression among duplicated genes during sorghum-Bipolaris sorghicola interaction. BMC Plant Biol. 12:121.

Moghimi, N., Desai, J. S., Bheemanahalli, R., Impa, S. M., Vennapusa, A. R., Sebela, D., Perumal, R., Doherty, C. J., and Jagadish, S. V. K. 2019. New candidate loci and marker genes on chromosome 7 for improved chilling tolerance in sorghum. J. Exp. Bot. 70:3357-3371.

Nicholson, R. L., Kollipara, S. S., Vincent, J. R., Lyons, P. C., and CadenaGomez, G. 1987. Phytoalexin synthesis by the sorghum mesocotyl in response to infection by pathogenic and nonpathogenic fungi. Proc. Natl. Acad. Sci. U.S.A. 84:5520-5524.

Nielsen, K. A., Gotfredsen, C. H., Buch-Pederson, M. J., Ammitzbøll, H., Mattsson, O., Duus, J. Ø., and Nicholson, R. L. 2004. Inclusions of flavonoid 3-deoxyanthocyanidins in Sorghum bicolor self-organize into spherical structures. Physiol. Mol. Plant Pathol. 65:187-196.

Nieminen, J. K., and Setala, H. 2001. Bacteria and microbial-feeders modify the performance of a decomposer fungus. Soil Biol. Biochem. 33:1703-1712.

Oberholster, T., Vikram, S., Cowan, D., and Valverde, A. 2018. Key microbial taxa in the rhizosphere of sorghum and sunflower grown in crop rotation. Sci. Total Environ. 624:530-539.

Oksanen, J., Blanchet, F. G., Friendly, M., Kindt, R., Legendre, P., McGlinn, D., Minchin, P. R., O’Hara, R. B., Simpson, G. L., Solymos, P., Stevens, M. H. H., Szoecs, E., and Wagner, H. 2019. vegan: Community ecology package. R package version 2.5-5. https://cran.r-project.org/web/packages/vegan/index. html

Parra-Londono, S., Fiedler, K., Kavka, M., Samans, B., Wieckhorst, S., Zacharias, A., and Uptmoor, R. 2017. Genetic dissection of early-season cold tolerance in sorghum: Genome-wide association studies for seedling emergence and survival under field and controlled environmental conditions. Appl. Genet. 131:581-595.

Pedersen, J. F., and Toy, J. J. 2001a. Registration of N321-N340 sorghum seed color/plant color genetic stocks. Crop Sci. 41:607.

Pedersen, J. F., and Toy, J. J. 2001b. Germination, emergence, and yield of 20 plant-color, seed-color near-isogenic lines of grain sorghum. Crop Sci. 41: 107-110.

Pesaro, M., Widmer, F., Nicollier, G., and Zeyer, J. 2003. Effects of freeze-thaw stress during soil storage on microbial communities and methidathion degradation. Soil Biol. Biochem. 35:1049-1061.

Petrovic, T., Walsh, J. L., Burgess, L. W., and Summerell, B. A. 2009. Fusarium species associated with stalk rot of grain sorghum in the northern grain belt of eastern Australia. Australas. Plant Pathol. 38:373-379.

Prins, T. W., Tudzynski, P., von Tiedemann, A., Tudzynski, B., Ten Hanve, A., Hansen, M. E., Tenberge, K., and van Kan, J. A. L. 2000. Infection strategies of Botrytis cinereal and related necrotrophic pathogens. Pages 33-64 in: Fungal Pathology. J. W. Kronstrad, ed. Springer, Dordrecht, The Netherlands.

Qiao, Q., Zhang, J., Ma, C., Wang, F., Chen, Y., Zhang, C., Zhang, H., and Zhang, J. 2019. Characterization and variation of the rhizosphere fungal community structure of cultivated tetraploid cotton. PLoS One 14: e0207903.

Quast, C., Pruesse, E., Yilmaz, P., Gerken, J., Schweer, T., Yarza, P., Peplies, J., and Glöckner, F. O. 2013. The SILVA ribosomal RNA gene database project: Improved data processing and web-based tools. Nucleic Acids Res. 41: D590-D596.

Ramond, J.-B., Tshabuse, F., Bopda, C. W., Cowan, D. A., and Tuffin, M. I. 2013. Evidence of variability in the structure and recruitment of rhizospheric and endophytic bacterial communities associated with arable sweet sorghum (Sorghum bicolor (L) Moench). Plant Soil 372:265-278.

Reddy, B. V., Reddy, P. S., Sadananda, A. R., Dinakaran, E., Ashok, K., Deshpande, S. P., Srinivasa Rao, P., Sharma, H. C., Sharma, R., Krishnamurthy, L., and Patil, J. V. 2012. Postrainy season sorghum: Constraints and breeding approaches. J. SAT Agric. Res. 10:1-12.

Reddy, B. V. S., and Reddy, P. S. 2003. Sweet sorghum: Characteristics and potential. Sorghum Millets Newsl. 44:26-28.
Reed, J. E., Partridge, J. E., and Nordquist, P. T. 1983. Fungal colonization of stalks and roots of grain sorghum during the growing season. Plant Dis. 67: 417-420.

Rhodes, D., Gadgil, P., Perumal, R., Tesso, T., and Herald, T. J. 2017. Natural variation and genome-wide association study of antioxidants in a diverse sorghum collection. Cereal Chem. J. 94:190-198.

Rodriguez-Sanchez, A., Muñoz-Palazon, B., Hurtado-Martinez, M., Rivadeneyra, M. A., Poyatos, J. M., and Gonzalez-Lopez, J. 2018. Maximum influent salinity affects the diversity of mineral-precipitation-mediating bacterial communities in membrane biofilm of hybrid moving bed biofilm reactor-membrane bioreactor. Water Air Soil Pollut. 229:342.

Rooney, W. L., Blumenthal, J., Bean, B., and Mullet, J. E. 2007. Designing sorghum as a dedicated bioenergy feedstock. Biofuels Bioprod. Biorefin. 1: $147-157$

Roozeboom, K., and McKinney, L. 2009. Harvesting grain from freeze-damaged sorghum. Kansas State University, Department of Agronomy, Agricultural Experiment Station and Cooperative Extension Service. https://www.agronomy.kstate.edu/extension/crop-production/grain-sorghum/freeze-damage/index.html

Sajeli Begum, A., Basha, S. A., Raghavendra, G., Kumar, M. V. N., Singh, Y., Patil, J. V., Tanemura, Y., and Fujimoto, Y. 2014. Isolation and characterization of antimicrobial cyclic dipeptides from Pseudomonas fluorescens and their efficacy on sorghum grain mold fungi. Chem. Biodivers. 11:92-100.

Sauder, L. A., Albertsen, M., Engel, K., Schwarz, J., Nielsen, P. H., Wagner, M., and Neufeld, J. D. 2017. Cultivation and characterization of Candidatus Nitrosocosmicus exaquare, an ammonia-oxidizing archaeon from a municipal wastewater treatment system. ISME J. 11:1142-1157.

Schimel, J., Balser, T. C., and Wallenstein, M. 2007. Microbial stress-response physiology and its implications for ecosystem function. Ecology 88: 1386-1394.

Schimel, J. P., and Clein, J. S. 1996. Microbial response to freeze-thaw cycles in tundra and taiga soils. Soil Biol. Biochem. 28:1061-1066.

Schittenhelm, S., and Schroetter, S. 2014. Comparison of drought tolerance of maize, sweet sorghum, and sorghum-sudangrass hybrids. J. Agron. Crop Sci. 200:46-53.

Schlemper, T. R., Leite, M. F. A., Lucheta, A. R., Shimels, M., Bouwmeester, H. J., van Veen, J. A., and Kuramae, E. E. 2017. Rhizobacterial community structure differences among sorghum cultivars in different growth stages and soils. FEMS Microbiol. Ecol. 93.

Schlemper, T. R., van Veen, J. A., and Kuramae, E. E. 2018. Co-variation of bacterial and fungal communities in different sorghum cultivars and growth stages is soil dependent. Microb. Ecol. 76:205-214.

Schmalenberger, A., Hodge, S., Bryant, A., Hawkesford, M. J., Singh, B. K., and Kertesz, M. A. 2008. The role of Variovorax and other Comamonadaceae in sulfur transformations by microbial wheat rhizosphere communities exposed to different sulfur fertilization regimes. Environ. Microbiol. 10:1486-1500.

Schulz, E., Tohge, T., Zuther, E., Fernie, A. R., and Hincha, D. K. 2016. Flavonoids are determinants of freezing tolerance and cold acclimation in Arabidopsis thaliana. Sci. Rep. 6:34027.

Shaw, L. J., Morris, P., and Hooker, J. E. 2006. Perception and modification of plant flavonoid signals by rhizosphere microorganisms. Environ. Microbiol. 8:1867-1880.

Sheflin, A. M., Chiniquy, D., Yuan, C., Goren, E., Kumar, I., Braud, M., Brutnell, T., Eveland, A. L., Tringe, S., and Liu, P. 2019. Metabolomics of sorghum roots during nitrogen stress reveals compromised metabolic capacity for salicylic acid biosynthesis. Plant Direct 3:e00122.

Singh, S. P. 1985. Sources of cold tolerance in grain sorghum. Can. J. Plant Sci. 65:251-257.

Snyder, B. A., Leite, B., Hipskind, J., Butler, L. G., and Nicholson, R. L. 1991. Accumulation of sorghum phytoalexins induced by Colletotrichum graminicola at the infection site. Physiol. Mol. Plant Pathol. 39:463-470.

Staggenborg, S. A., and Vanderlip, R. L. 1996. Sorghum grain yield reductions caused by duration and timing of freezing temperatures. Agron. J. 88: 473-477.

Staggenborg, S. A., Vanderlip, R. L., Roggenkamp, G. J., and Kofoid, K. D. 1999. Methods of simulating freezing damage during sorghum grain fill. Agron. J. 91:46-53.

Steinkellner, S., Lendzemo, V., Langer, I., Schweiger, P., Khaosaad, T., Toussaint, J.-P., and Vierheilig, H. 2007. Flavonoids and strigolactones in root exudates as signals in symbiotic and pathogenic plant-fungus interactions. Molecules 12:1290-1306.

Tang, X., Luo, S., Huang, Z., Wu, H., Wang, J., Shi, G., He, L., Xiong, F., Jiang, J., Liu, J., Liao, G., Tang, R., and He, L. 2019. Changes in the physicochemical properties and microbial communities of rhizospheric soil after cassava/peanut intercropping. bioRxiv. doi:10.1101/570937 
Tattini, M., Guidi, L., Morassi-Bonzi, L., Pinelli, P., Remorini, D., Degl'Innocenti, E., Giordano, C., Massai, R., and Agati, G. 2005. On the role of flavonoids in the integrated mechanisms of response of Ligustrum vulgare and Phillyrea latifolia to high solar radiation. New Phytol. 167:457-470.

Tayyaba, Y., and Muhammad, F. 2015. Molecular characterization of plant growth promoting bacterial strains from Pinus roxburghii L. rhizosphere. Res. J. Biotechnol. 10:54-61.

Tetreault, H. M., Grover, S., Scully, E. D., Gries, T., Palmer, N. A., Sarath, G., Louis, J., and Sattler, S. E. 2019. Global responses of resistant and susceptible sorghum (Sorghum bicolor) to sugarcane aphid (Melanaphis sacchari). Front. Plant Sci. 10:145.

Treutter, D. 2006. Significance of flavonoids in plant resistance: A review. Environ. Chem. Lett. 4:147-157.

Tsolakidou, M.-D., Stringlis, I. A., Fanega-Sleziak, N., Papageorgiou, S., Tsalakou, A., and Pantelides, I. S. 2019. Rhizosphere-enriched microbes as a pool to design synthetic communities for reproducible beneficial outputs. FEMS Microbiol. Ecol. 95:fiz138.

UNITE Community. 2019. UNITE general FASTA release for Fungi 2. Version 18.11.2018. UNITE Community. doi:10.15156/BIO/786353

Vidhyasekaran, P. and Muthamilan, M. 1995. Development of formulations of Pseudomonas fluorescens for control of chickpea wilt. Plant Dis. 79: 782-786.

Weller, D. M. 2007. Pseudomonas biocontrol agents of soilborne pathogens: Looking back over 30 years. Phytopathology 97:250-256.

White, L. J., Ge, X., Brözel, V. S., and Subramanian, S. 2017. Root isoflavonoids and hairy root transformation influence key bacterial taxa in the soybean rhizosphere. Environ. Microbiol. 19: 1391-1406.
Winkel-Shirley, B. 2001. Flavonoid biosynthesis. A colorful model for genetics, biochemistry, cell biology, and biotechnology. Plant Physiol. 126:485-493.

Wood, A. W., Tan, D. K. Y., Mamun, E. A., and Sutton, B. G. 2006. Sorghum can compensate for chilling-induced grain loss. J. Agron. Crop Sci. 192:445-451.

Wu, G., Johnson, S. K., Bornman, J. F., Bennett, S. J., and Fang, Z. 2017. Changes in whole grain polyphenols and antioxidant activity of six sorghum genotypes under different irrigation treatments. Food Chem. 214:199-207.

Yang, Y., Zuzak, K., Harding, M., Neilson, E., Feindel, D., and Feng, J. 2017. First report of pink root rot caused by Setophoma (Pyrenochaeta) terrestris on canola. Can. J. Plant Pathol. 39:354-360.

Zhang, F. B., Zheng, H. L., Cui, W. G., Zhang, M. Q., Yin, Y. S., Cui, M., and Gao, M. 2019. First report of Setophoma terrestris causing pink root of garlic in China. Plant Dis. 103:584.

Zhang, H., Wu, X., Li, G., and Qin, P. 2011. Interactions between arbuscular mycorrhizal fungi and phosphate-solubilizing fungus (Mortierella sp.) and their effects on Kostelelzkya virginica growth and enzyme activities of rhizosphere and bulk soils at different salinities. Biol. Fertil. Soils 47:543.

Zhang, J., Kim, Y.-J., Hoang, V.-A., Nguyen, N. L., Wang, C., Kang, J.-P., Wang, D., and Yang, D.-C. 2016. Duganella ginsengisoli sp. no., isolated from ginseng soil. Int. J. Syst. Evol. Microbiol. 66:56-61.

Zhang, L.-N., Wang, D.-C., Hu, Q., Dai, X.-Q., Xie, Y.-S., Li, Q., Liu, H.-M., and Guo, J.-H. 2019. Consortium of plant growth-promoting rhizobacteria strains suppresses sweet pepper disease by altering the rhizosphere microbiota. Front. Microbiol. 10:1668.

Zhang, T., Wang, Z., Lv, X., Li, Y., and Zhuang, L. 2019. High-throughput sequencing reveals the diversity and community structure of rhizosphere fungi of Ferula sinkiangensis at different soil depths. Sci. Rep. 9:6558. 